\title{
MRS International: Coping with New Dimensions
}

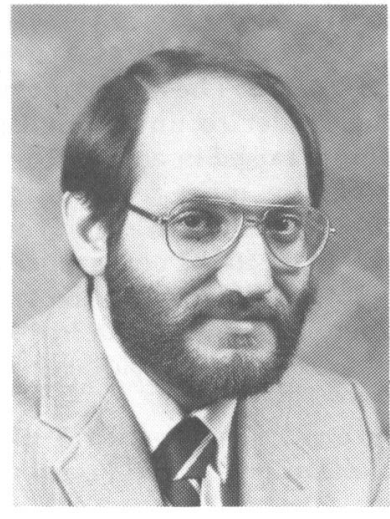

As any avid reader of the MRS BULLETIN knows, we are continually reminding our readers and ourselves of the multidimensional breadth spanned by the Society's mission. MRS spans research from the basic to the applied. It deals in materials ranging from concrete to coal to catalysts, from metals to semiconductors to insulators, and so forth. Topics as disparate as nuclear waste containment and energybeam processing appear together on our programs. And, presentations of research at our meetings, and soon in the new Journal of Materials Research, come from each of the major scientific disciplines, individually and combined. It all works well because underlying the diversity is the unity of approach and technique common to materials research - a unity which imbues the work in distant subspecialties with relevance to our own.

The spreading recognition of the value of encompassing broad segments along the basic-applied, topical, material, and discipline dimensions has spurred the formation of MRS-Europe and is also pointing toward similar activities in Asia and the Pacific Basin. There are, however, yet additional dimensions to consider when in the truly international context. MRS events in the United States are international in attendance but not in organization or logistical support. When Dan Ehrlich, Walter Brown, and we recently attended the meeting of MRS-Europe in Strasbourg, we were struck by the need exhibited there to also span the multilingual and multinational dimension. We have all done this with relative ease in the context of scientific exchanges and that is to the credit of our calling. But, when questions of organizational structure, venue, funding, legal status, and the like arise, new challenges analogous to those well known in the councils of nations are faced.

Our colleagues in MRS-Europe are now tackling these issues with increased tenacity
Elton N. Kaufmann,

MRS President

Clifton W. Draper MRS Treasurer

and very visible advances are on the horizon. In the crucial area of the legal status of the organization, a preliminary version of a set of statutes (called a constitution in the United States) was presented at the meeting of the European Committee on May 14. Its language is French and once a final version is accepted, it will be the basis for legalizing MRS-Europe under the relevant laws of France. This is a natural and practical choice because the meetings have run and are continuing to run in Strasbourg.

It was interesting to observe, however that the scientists present and discussing the document were in many cases handicapped by the language, even though they were fluent in more than their native tongue. It turns out that to be fluent as a scientist in both French and English, for example, in no way guarantees that one can translate legal terminologies faithfully. The document has been referred to a committee, comprised of Drs. von Allmen, Krimmel, Laude, Rimini, Rodot, Sirtl, and Speight, and will be reported back soon. In the meantime, through the good offices of the Council of Europe and Dr. J. P. Masue, an English reference version is being prepared. The text of the founding document will be reproduced in the pages of the BULLETIN as soon as it is ratified.

The need to identify reliable sources of external funding beyond meeting registration fees also doubly plagues the multinational group. Transport of individual government support across national boundaries appears very difficult. There is reason to believe some form of subsidy might arise from cooperation in programs of existing multinational entities such as the Council of Europe or the European Economic Community. Corporate support is fraught with far fewer complications, however, and was named by the European Committee as a potential to be pursued. In charge of the pursuit is a committee chaired by E. Krimmel of Siemens and comprising the several

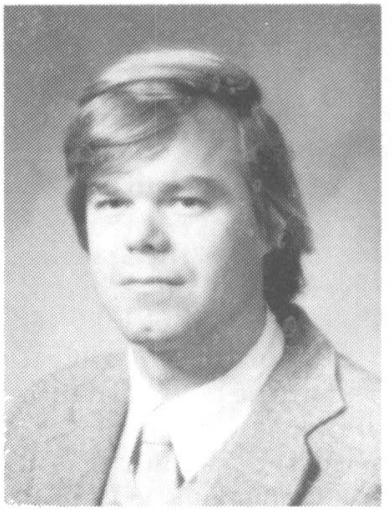

national representatives. We would expect that the very clear connection of the topics of the upcoming Fall meeting of MRSEurope to industrially relevant issues will aid in this quest.

There are, of course, existing models for the multinational organization. The European Physical Society is one. EPS was, in fact, represented at the MRS-Europe Commit tee meeting by its president and agreed to enter into some co-sponsorships with MRS for future meetings. The constitution and bylaws of the EPS were used as a model for the proposed statutes mentioned above.

Interesting additional multinational opportunities may be around the corner for MRS-Europe as well. The Council of European Ministers of Research (a rough analog of the U.S. NSF) is defining a set of "networks" for the exchange of information, and the support of research and training in about 20 technical areas, one of which is materials research. MRS-Europe appears to be the ideal focal point for the materials research network initiative

At the more mundane level, but of equal importance to the health of the organization, is the job of simply communicating efficiently within the organization. Here too there exist subtle inconveniences which arise from the lingual and national boundaries. During the meeting of the MRSEurope Committee, explicit recognition was afforded this problem, and it was resolved to put forth a concerted effort to improve and increase the communication channels among the many enthusiastic and expert volunteers.

We do not envy the added dimensions encompassed by our colleagues in Europe, but we applaud their current efforts at spanning them and are confident in their future success.

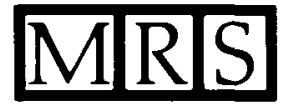

